\title{
Note
}

\section{Oxidative Adsorption of Arsenic by $N$-Methylglucamine-modified Chelate Fiber and Manganese Dioxide}

\author{
Atsushi KURAOKA, Toshiyuki UMEBAYASHI, Syouhei NISHIHAMA \\ and Kazuharu YOSHIZUKA* \\ Department of Chemical Engineering, The University of Kitakyushu, Hibikino 1-1, Kitakyushu 808-0135, Japan
}

(Manuscript received March 30, 2018; accepted May 2, 2018)

\begin{abstract}
We investigated removal of arsenic (As) from water using a combination of adsorption on a $N$ methylglucamine-modified chelate fiber and oxidation of As(III) to As(V) by manganese dioxide. Batch experiments revealed that the chelate fiber had high selectivity for As(V) over As(III), especially in the acidic $\mathrm{pH}$ region, because of differences in the species distribution of As in an aqueous solution. Oxidative and selective adsorption of As(III) was achieved when manganese dioxide was added to the adsorption system with the chelate fiber. The oxidative adsorption could be performed using the connected columns of the manganese dioxide and the chelate fiber. As(III) in the aqueous feed solution was oxidized to $\mathrm{As}(\mathrm{V})$ as it passed through the manganese dioxide column, and this was followed by adsorption of $\mathrm{As}(\mathrm{V})$ in the chelate fiber column. This method provides a simple removal method of As, as both $\mathrm{As}(\mathrm{III})$ and $\mathrm{As}(\mathrm{V})$, from water.
\end{abstract}

Keywords: Arsenic, Oxidative adsorption, $N$-Methylglucamine, Manganese dioxide

\section{Introduction}

Arsenic (As), a well-known toxic element, mainly exists as a sulfide ore $\left(\mathrm{As}_{2} \mathrm{~S}_{3}\right.$ and $\left.\mathrm{As}_{3} \mathrm{~S}_{4}\right)$ or sulfate ore (FeAsS) in nature ${ }^{1)}$. From these ores, it can leach into groundwater and diffuse into the environment. Most As in water is present as As(III) or $\mathrm{As}(\mathrm{V})$. The toxicity of $\mathrm{As}(\mathrm{III})$ is 25 to 60 times that of $\mathrm{As}(\mathrm{V})^{2)}$. The World Health Organization has established a limit of 0.01 $\mathrm{mg} / \mathrm{L}$ for As in drinking water. As contamination in groundwater is problematic worldwide, and removal of As from water is required. Several methods have been reported for removal of As from water, including coprecipitation ${ }^{3)}$, reverse osmosis $^{4)}$, and adsorption. Coprecipitation results in precipitation of a chemically unstable form of As, and separation of the precipitate and water is complicated ${ }^{4)}$. Reverse osmosis has high energy consumption and requires complicated sample processing.

The adsorption method is an excellent method for removal of As because it is safe, inexpensive, simple, and creates only small quantities of waste. Several adsorbents for As have been reported, including activated alumina ${ }^{5)}$, iron oxide ${ }^{6}$, titanium oxide $^{7)}$, and ion exchange resins ${ }^{8}$. The activated alumina, iron oxide, and titanium oxide adsorbents have high adsorption affinities for $\mathrm{As}(\mathrm{III})$, whereas ion exchange resins have high adsorption affinities for $\mathrm{As}(\mathrm{V})$. Recently, adsorbents modified with a $N$-methylglucamine group have attracted attention because the ligand selectively adsorbs $\operatorname{As}(\mathrm{V})$. The chelate fiber Chelest fiber GRY-HW is an adsorbent modified with a $N$ methylglucamine group on the surface of its cellulose fibers. This fiber provides removal of $\mathrm{As}(\mathrm{V})$, but further processing of the water is required for removal of As(III).

Oxidation of $\mathrm{As}(\mathrm{III})$ during adsorption is a promising method for the complete removal of As from water. Several oxidizing reagents, including potassium permanganate ${ }^{9}$, potassium peroxodisulfate ${ }^{10)}$, ozone ${ }^{11)}$, and hydrogen peroxide $^{12)}$, have been reported for $\mathrm{As}(\mathrm{III})$, but they are expensive.

\footnotetext{
* Corresponding author

E-mail: yoshizuka@kitakyu-u.ac.jp
} 
In the present work, we investigated oxidative adsorption of As from water using Chelest fiber as the adsorbent and manganese dioxide as an oxidizing reagent. Adsorption of $\mathrm{As}(\mathrm{III})$ and $\mathrm{As}(\mathrm{V})$ with the Chelest fiber was investigated first, and then oxidative adsorption of As(III) was conducted a batch experiments. Finally, oxidative adsorption of As in a chromatography adsorption system was investigated using connected columns containing manganese dioxide and the Chelest fiber.

\section{Experimental}

\subsection{Reagents}

Chelest fiber GRY-HW (Chelest Co., Osaka) was used as an adsorbent. The fiber was conditioned by washing twice with hydrochloric acid and deionized water in sequence. Manganese dioxide $\left(\mathrm{Li}_{1.5} \mathrm{Mn}_{2} \mathrm{O}_{4}\right.$, JGC Catalysts and Chemicals Ltd., Kanagawa) was washed twice with hydrochloric acid and deionized water in sequence. Aqueous solutions of As were prepared by dissolving $\mathrm{NaAsO}_{2}$ (Wako Pure Chemical Industries) or $\mathrm{Na}_{2} \mathrm{HAsO}_{4} \cdot 7 \mathrm{H}_{2} \mathrm{O}$ (Alfa Aesar) in deionized water.

\subsection{Batch adsorption experiments}

Batch adsorption experiments were carried out by shaking an As solution $(10 \mathrm{~mL})$ with Chelest fiber $(20 \mathrm{mg})$ for $24 \mathrm{~h}$. The $\mathrm{pH}$ of the aqueous solution was adjusted with either hydrochloric acid or sodium hydroxide solution. The total concentration of As remaining in the aqueous solution was determined by ICP-AES (Shimadzu ICPE-9000).

\subsection{Column adsorption experiments}

In the column system, manganese dioxide was granulated with alumina binder (Cataloid AP-1, JGC Catalysts and Chemicals). An aqueous feed solution containing both As(III) and $\mathrm{As}(\mathrm{V})([\mathrm{As}(\mathrm{III})]+[\mathrm{As}(\mathrm{V})]=0.1 \mathrm{mmol} / \mathrm{L})$ was continuously supplied to connected columns containing the granulated manganese dioxide and Chelest fiber. The space velocity of the solution was $20 \mathrm{~h}^{-1}$ for the manganese dioxide and $27 \mathrm{~h}^{-1}$ for the Chelest fiber. After reaching adsorption saturation, the Chelest fiber column was eluted with $2 \mathrm{~mol} / \mathrm{L}$ hydrochloric acid. The concentration of metal ions in the eluate was determined by ICP-AES.

\section{Results and Discussion}

\subsection{Batchwise adsorption of arsenic with Chelest fiber}

Batchwise adsorption of $\mathrm{As}(\mathrm{III})$ and $\mathrm{As}(\mathrm{V})$ with Chelest fiber from separate solutions was investigated first. The effect of $\mathrm{pH}$ on the amounts $(q)$ of $\mathrm{As}(\mathrm{III})$ and $\mathrm{As}(\mathrm{V})$ adsorbed was evaluated (Fig. 1). For As(III), almost no adsorption was observed at $\mathrm{pH}<6$ and minimal adsorption occurred at $\mathrm{pH}>6$. For $\mathrm{As}(\mathrm{V})$, high adsorption was observed at $\mathrm{pH}<6$, and the adsorption amount decreased at $\mathrm{pH}>6$. Next, we investigated the species distribution of $\mathrm{As}(\mathrm{III})$ and $\mathrm{As}(\mathrm{V})$ in the aqueous solution (Fig. 2) ${ }^{13)}$. For As(III), the predominant species at $\mathrm{pH}$
$<6$ was neutral $\mathrm{H}_{3} \mathrm{AsO}_{3}$, and anionic $\mathrm{H}_{2} \mathrm{AsO}_{3}{ }^{-}$appeared at $\mathrm{pH}$ $>$ 6. For $\mathrm{As}(\mathrm{V})$, the predominant species at $\mathrm{pH}<6$ was monovalent $\mathrm{H}_{2} \mathrm{AsO}_{4}{ }^{-}$, and divalent $\mathrm{HAsO}_{4}{ }^{2-}$ appeared at $\mathrm{pH}>$ 6. Therefore, the Chelest fiber shows affinity for monovalent anionic species, and the difference in the adsorption amounts between $\mathrm{As}(\mathrm{III})$ and $\mathrm{As}(\mathrm{V})$ could be attributed to the distribution of As species in the aqueous solution.

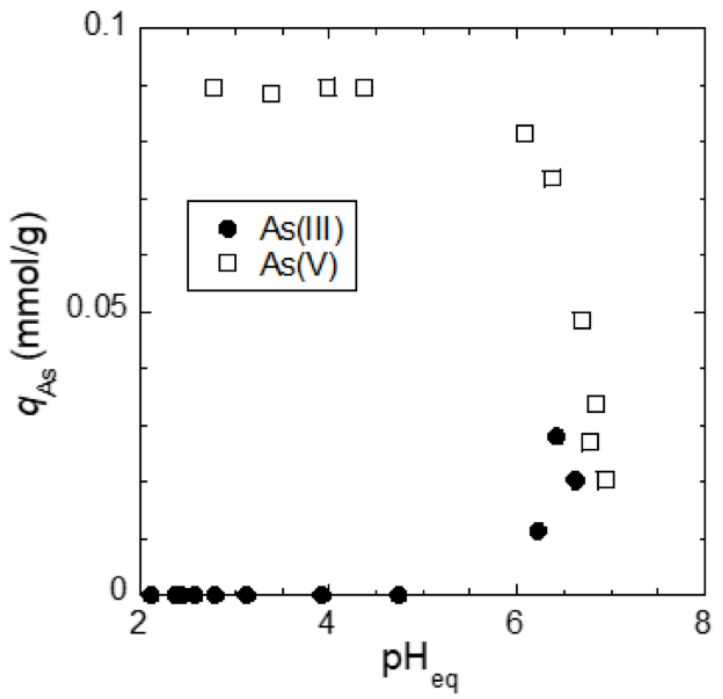

Fig. 1 Effect of $\mathrm{pH}$ on the amounts of $\mathrm{As}(\mathrm{III})$ and $\mathrm{As}(\mathrm{V})$ adsorbed by Chelest fiber.

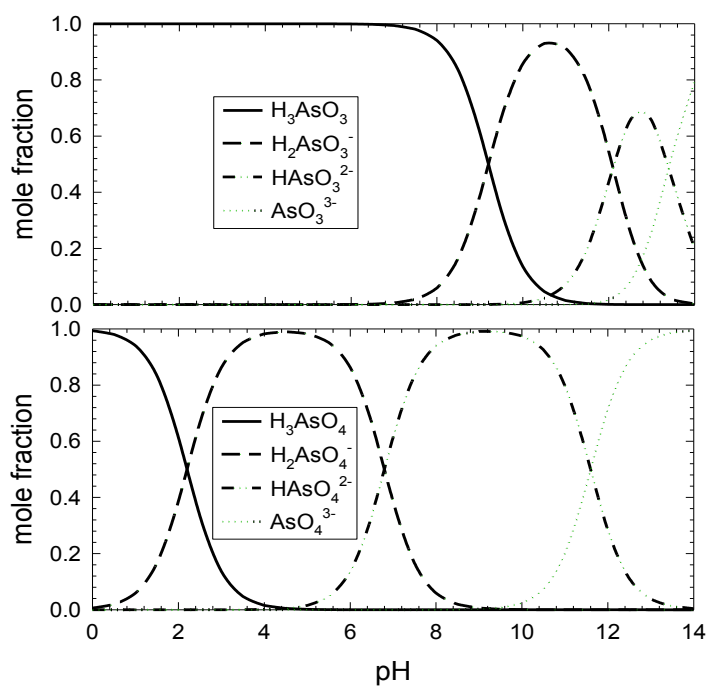

Fig. 2 Distributions of (a) As(III) and (b) As(V) species in aqueous solution ${ }^{13)}$.

\subsection{Oxidative adsorption of As(III)}

We then investigated oxidative adsorption of As(III) with Chelest fiber and manganese dioxide and compared it with conventional adsorption of $\mathrm{As}(\mathrm{V})$ with only the Chelest fiber (Fig. 3). Oxidation of $\mathrm{As}(\mathrm{III})$ to $\mathrm{As}(\mathrm{V})$ with manganese dioxide was successful, and the $\mathrm{As}(\mathrm{V})$ produced was adsorbed on the fiber. Therefore, the oxidative adsorption of As(III) was almost 


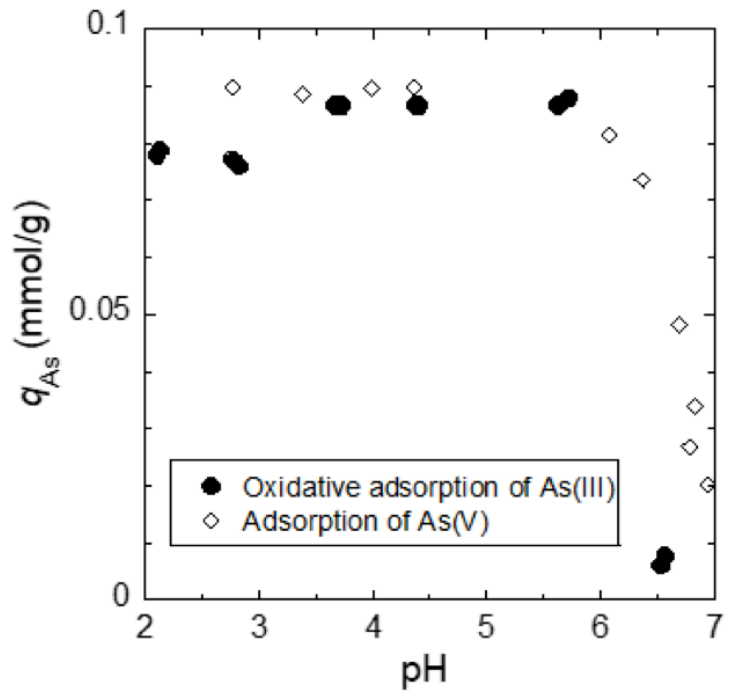

Fig. 3 Comparison of oxidative adsorption of As(III) with manganese dioxide and conventional adsorption of As(V) with Chelest fiber.

the same as the adsorption of $\mathrm{As}(\mathrm{V})$. The oxidative adsorption system with manganese dioxide and Chelest fiber shows potential for effective removal of As from water.

\subsection{Oxidative adsorption of As with the connected column} system

Finally, we investigated the oxidative adsorption using the column system. In this system, columns of granulated manganese dioxide and Chelest fiber were connected in series. Then, a mixture of $\mathrm{As}(\mathrm{III})$ and $\mathrm{As}(\mathrm{V})$ was supplied to the connected columns. Breakthrough and elution curves of As were recorded (Fig. 4). Oxidative adsorption of As was achieved even in the chromatographic adsorption system, and As could be completely adsorbed until the bed volume was approximately 10,000. Elution of the adsorbed As from the Chelest fiber was also achieved. The amount adsorbed was $0.672 \mathrm{mmol} / \mathrm{g}$, and the amount eluted was $0.647 \mathrm{mmol} / \mathrm{g}$, which gave an elution yield of $96.2 \%$. Therefore, the oxidative

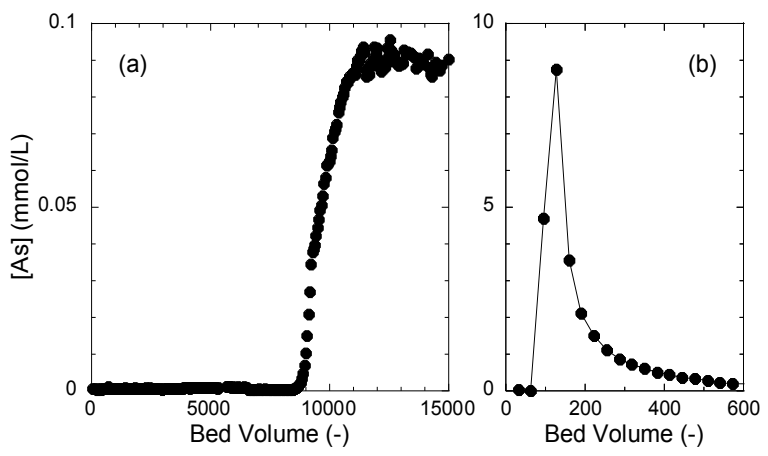

Fig. 4 (a) Breakthrough curve and (b) elution curve of As. Adsorption behavior of $\mathrm{As}(\mathrm{III})$ and $\mathrm{As}(\mathrm{V})$ by oxidative adsorption with manganese dioxide and Chelest fiber. adsorption method using manganese dioxide and Chelest fiber can provide complete removal of As, as both $\mathrm{As}(\mathrm{III})$ and $\mathrm{As}(\mathrm{V})$, from water.

\section{Conclusions}

We evaluated Chelest fiber and manganese dioxide for oxidative adsorption of As. Chelest fiber has high adsorption ability for $\mathrm{As}(\mathrm{V})$ at $\mathrm{pH}<6$, but almost no adsorption of $\mathrm{As}(\mathrm{III})$ occurs. This difference in adsorption ability is caused by the species present in the aqueous solution. Manganese dioxide can successfully oxidize As(III) to As(V), and oxidative adsorption of As(III) is achieved with a combination of manganese dioxide and Chelest fiber. The oxidative adsorption of As can be conducted by connecting columns containing the different components in series.

\section{References}

1) K.B. Mandal and K.T. Suzuki, Talanta, 58, 201-235 (2002).

2) T.V. Nguyen, S. Vigneswaran, H.H. Ngo, J. Kandasamy and H.C. Choi, Purif. Technol., 61, 44-50 (2008).

3) US Environmental Protection Agency (US EPA), EPA542-S02-002, Office of Solid Waste Emergency (5102G), 200 (2002).

4) X.H. Guan, J. Wang and C.C. Chusuei, J. Hazard. Mater., 156, 178-185 (2008).

5) P.L. Smedley and D.G. Kinniburgh, Appl. Geochem., 17, 517-568 (2002).

6) V. Lenoble, O. Bouras, V. Deluchat, B. Serpaud and J.C. Bollinger, J. Colloid Interface Sci., 255, 52-58 (2002).

7) P.K. Dutta, A.K. Ray, V.K. Sharma and F.J. Millero, J. Colloid Interface Sci., 278, 270-275 (2004).

8) J. Kim and M.M. Benjamin, Water Res., 38, 2053-2062 (2004).

9) S. Sorlini and F. Gialdini, Water Res., 44, 5653-5659 (2010).

10) B. Neppolian, A. Doronila and M. Ashokkumar, Water Res., 44, 3687-3695 (2010).

11) M.-J. Kim and J. Nriagu, Sci. Total Environ., 247, 71-79 (2000).

12) M. Pettine and F.J. Millero, Mar. Chem., 70, 223-234 (2000).

13) H. Egawa, T. Nonaka and H. Maeda, Sep. Sci. Technol. Jpn., 20, 653-664 (1985). 